\title{
Development, characterization and analysis of auxetic structures from braided composites and study the influence of material and structural parameters
}

\author{
Rui Magalhaes ${ }^{a}$, P. Subramani ${ }^{\mathrm{b}}$, Tomas Lisner ${ }^{\mathrm{c}}$, Sohel Rana ${ }^{\mathrm{b}, *}$, Bahman Ghiassi $^{\mathrm{a}}$, Raul Fangueiro ${ }^{\mathrm{a}}$, \\ Daniel V. Oliveira ${ }^{a}$, Paulo B. Lourenco ${ }^{a}$ \\ a ISISE, Department of Civil Engineering, University of Minho, Guimarães, Portugal \\ ${ }^{\mathrm{b}}$ Center for Textile Science and Technology, University of Minho, Guimarães, Portugal \\ ${ }^{\mathrm{c}}$ Department of Nonwovens and Nanofibrous Materials, Technical University of Liberec, Liberec, Czech Republic
}

\section{A R T I C L E I N F O}

\section{Article history:}

Received 4 November 2015

Received in revised form 18 April 2016

Accepted 19 April 2016

Available online 20 April 2016

\section{Keywords:}

B. Mechanical properties

C. Analytical modelling

D. Mechanical testing

E. Braiding

\begin{abstract}
A B S T R A C T
Auxetic materials are gaining special interest in technical sectors due to their attractive mechanical behaviour. This paper reports a systematic investigation on missing rib design based auxetic structures produced from braided composites for civil engineering applications. The influence of various structural and material parameters on auxetic and mechanical properties was thoroughly investigated. The basic structures were also modified with straight longitudinal rods to enhance their strengthening potential in structural elements. Additionally, a new analytical model was proposed to predict Poisson's ratio through a semi empirical approach. Auxetic and tensile behaviours were also predicted using finite element analysis. The auxetic and tensile behaviours were observed to be more strongly dependent on their structural parameters than the material parameters. The developed analytical models could well predict the auxetic behaviour of these structures except at very low or high strains. Good agreement was also observed between the experimental results and numerical analysis.
\end{abstract}

(c) 2016 Elsevier Ltd. All rights reserved.

\section{Introduction}

Poisson's ratio is defined as the lateral strain to the longitudinal strain for a materials undergoing tension in the longitudinal direction. In common, all materials possess positive Poisson's ratio, i.e. the materials shrink laterally under tensile loading, and expand transversely when compressed. However, in auxetic materials the phenomena is just reverse, i.e. when material stretched it expands transversely and contracts during compression that is, they exhibit negative Poisson's ratio (NPR) [1-9]. Negative Poisson's ratios are theoretically accepted. For an isotropic material, the range of Poisson's ratio is from -1.0 to 0.5 , based on thermodynamic consideration of strain energy in the theory of elasticity. However, for anisotropic materials, these range is higher and limits do not apply $[2,6,10]$.

Auxetic materials gains specific interest due to their unusual behaviour which results improved mechanical properties, such as improved fracture toughness, higher indentation resistance, high

\footnotetext{
* Corresponding author at: Centre for Textile Science and Technology, University of Minho, Azurem Campus, 4800-058 Guimaraes, Portugal.

E-mail address: soheliitd2005@gmail.com (S. Rana).
}

energy absorption, sound absorption properties, improved shear modulus, hardness, synclastic curvature (dome shape on out-ofplane flexure) in sheets and panels, high volume change, high impact resistance, etc. [2,6-9,11-13].

Diverse range of auxetic materials includes, naturally occurred pyrolytic graphite, cancellous bone, rock with micro-cracks, auxetic three dimensional foams, auxetic bio-materials, auxetic twodimensional honeycomb, auxetic composites (fibre reinforced plastics or FRPs) auxetic microporous polymers, etc. [2,6,9$11,14]$. Auxetic textile materials are widely used as filter, sports clothing, biomedical application, defense industries, etc. Also, auxetic composites can find potential applications in aerospace and automotive industry as well as in materials for protection, where non-auxetic composites with high specific strength and stiffness are currently used $[2,6,8,10-12,15]$.

Besides composites, the auxetic property can also be attained with definite structural designs. In the last few decades, divergent geometric structures and models exhibiting auxetic behaviour have been proposed, studied and tested for their mechanical properties. The main auxetic structures reported are two dimensional (2D) and three dimensional (3D) re-entrant structures, rotating 


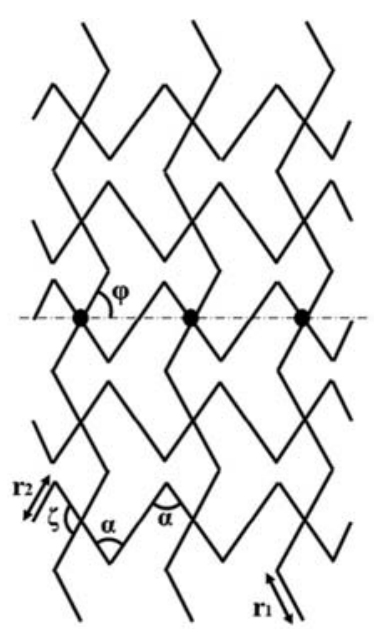

(a)

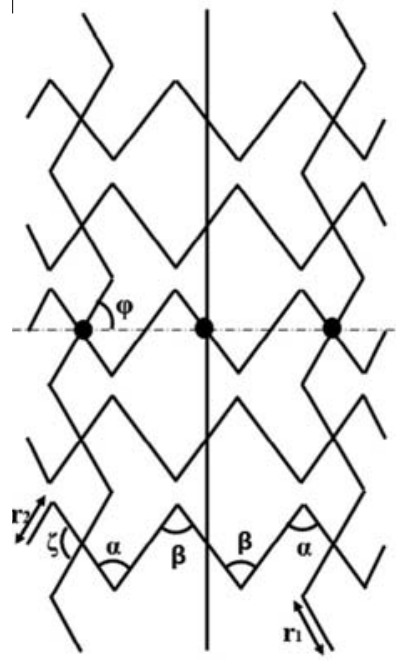

(d)

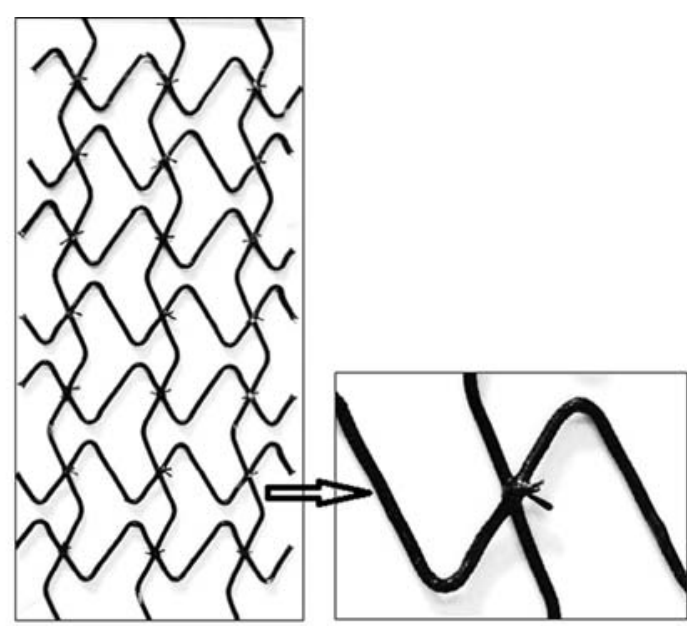

(c)

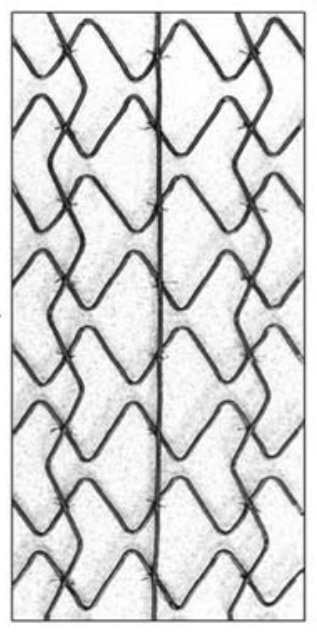

(e)

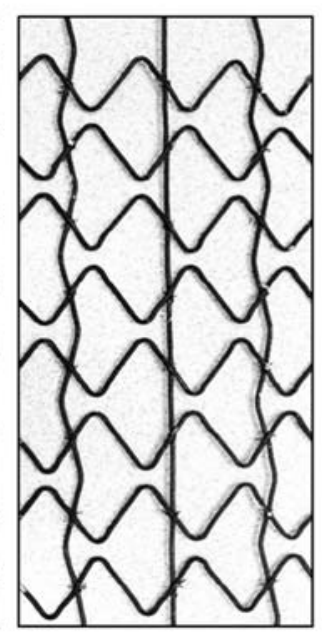

(f)

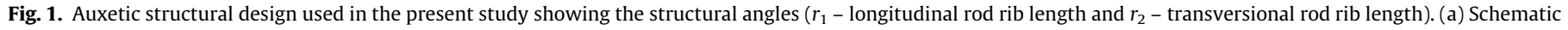
of structure-1, (b) real structure-1, (c) portion of structure in close-up, (d) schematic of structure-2 and (e and f) structure-2 and structure-3.

rigid/semi-rigid units, chiral and cross chiral structures, hard molecules, liquid crystalline polymers and microporous polymers $[6,7,11,14,16-20,21]$.

Fibre reinforced polymer composites have been applied widely in civil structural applications due to their enhanced properties as compared to conventional materials (concrete and steel) or ceramic based composites. These properties include high tenacity, low density, higher stiffness and strength, and easy handling. Composites are introduced into structural elements to improve their flexural resistance, shear strength, confinement, bending property, etc. [22-27]. Recently developed braided composite rods (BCRs) are a special class of FRPs, which have been used in structural applications due to their several advantages over the other types of FRPs such as simple and economical manufacturing process, tailorable mechanical properties and good bonding behaviour with cementitious matrices [28-33]. Currently, research is being carried out to employ composite materials in structural elements to improve their resistance against earthquake, blast or impact loads caused by explosions [34-37]. Capacity to absorb energy is one of the principal requirements for these applications and, in this sense, auxetic composites and structures may prove to be excellent materials.

In our previous research study, auxetic structures were developed from braided composite rods based on missing rib or lozenge grid or cross-chiral (Fig. 1a) design and their auxetic and tensile behaviours were studied, mainly focusing on the influence of structural angle [2]. Similar to other studies $[17,18]$, this initial study also showed that the structures based on the cross-chiral configuration exhibited negative Poisson's ratio. However, a recently performed analytical study revealed that the Poisson's ratio in the cross-chiral structures should be zero [20]. The equivalent negative Poisson's ratio which was observed in the experimental studies was the result of uniaxial shear coupling existing in these structures [20]. In contrast to our previous work [2], which only considered the influence of structural angle on auxetic and tensile behaviours, the influence of all important structural and material parameters has been considered in the present work. Moreover, the previous work considered the existing analytical model (based on the hinging mechanism, according to Refs. [17,18]) to predict the auxetic behaviour of developed structures leading to no correlation between the experimental and analytical results. To overcome this, in the present work a new analytical model (based on the hinging mechanism, but with additional parameters) has been proposed both for the basic and modified structures. Numerical modelling based on finite element (FE) method has also been performed to predict auxetic and tensile behaviours. Also, in the present case, the rib length of the structures has been decreased to increase their closeness and consequently, their strengthening capability for civil engineering applications. 
These structures were subjected to tensile loading in a Universal Testing Machine and auxetic behaviour (Poisson's ratio) was characterized by means of simple image analysis technique (using Image software). The influence of different structural parameters (angle $\varphi$, BCR diameter and addition of straight rods) and material parameters (type of fibres and linear density) on Poisson's ratio and tensile properties was thoroughly investigated.

\section{Materials and methods}

\subsection{Materials}

For the production of braided composite rods, glass fibre roving with linear density of 1200 tex and 4800 tex was purchased from Owens Corning, France. Also, basalt fibre roving with 4800 tex and carbon fibre roving with linear density of 1600 tex were purchased from Basaltex, Belgium and Toho Tenax, Germany, respectively and used to produce braided composites. The epoxy resin used to in this work was supplied by Sika, Germany, in two parts: Biresin CR83 Resin and Biresin CH-83-2 Hardner. The resin and hardener components were mixed in a weight ratio of 100:30 prior to use. The important properties of fibre and resin are given in Table 1.

\subsection{Fabrication of braided composite rods and auxetic structures}

Textile fibres reinforced braided structures were produced in a vertical braiding machine using polyester multi-filament yarns (with linear density of 110 tex) in the sheath and glass, basalt, and carbon multifilament rovings as the core material.

During the braiding process, sixteen polyester filament bobbins were used to supply the sheath yarns, which were braided around the core fibres to produce the braided structures [30-32]. Produced braided structures were then used to develop three types of auxetic structures, as shown in Fig. 1. First, structure-1 (Fig. 1b) was developed based on the missing rib or lozenge grid or crosschiral auxetic structural design (Fig. 1a). Second, the basic design was modified with longitudinal straight rod to improve the tensile behaviour termed structure-2. Third, structure- 2 was further modified to enhance the strengthening behaviour using undulation longitudinal rods with higher angle of inclinations, resulting in structure-3. In each type, four samples were produced with the total gauge length and width as $40 \mathrm{~cm}$ and $15 \mathrm{~cm}$, respectively, with extra length for clamping during tensile testing. The following are the steps used to develop auxetic structures mentioned above: (1) the auxetic structural design (Fig. 1a and d) was drawn on a white chart paper; (2) the chart paper was placed on a board and the braided structures were placed over the drawn design firmly with help of adhesive tape; (3) the cross-over points were tied by polyester filaments and epoxy resin was applied over the structures using a brush; (4) after curing, the structures were removed from the board. The braided structures after resin application and curing became circular composites termed as braided composite rods (BCR). The weight percentage of core fibres in each of these rods was around $51 \% \pm 2 \%$. Resin use was essential to provide adequate mechanical strength to the braided composites in order to

Table 1

Physical properties of core fibres and resin.

\begin{tabular}{llllll}
\hline S. no. & Properties & Basalt & Glass & Carbon & Epoxy \\
\hline 1 & Density $\left(\mathrm{g} / \mathrm{cm}^{3}\right)$ & 2.63 & 2.62 & 1.77 & 1.15 \\
2 & Filament diameter $(\mu \mathrm{m})$ & 17 & - & 13 & - \\
3 & Tensile strength $(\mathrm{MPa})$ & $>4000$ & $3100-3800$ & 4400 & 122 \\
4 & Tensile modulus $(\mathrm{GPa})$ & 87 & $80-81$ & 240 & 3.3 \\
5 & Elongation $(\%)$ & - & - & 1.8 & 6.7
\end{tabular}

handle them easily and turn them in to rigid auxetic structures. In addition, the braided structures exhibit appropriate mechanical property necessary for the directed use only after the resin application and formation of BCR, as the matrix embraces the different constituents (sheath and core fibres) of braided structure together, facilitating them to act as a single structure. In absence of resin, there may be slippage between the sheath and core as well as between the core fibres resulting in poor mechanical characteristics.

\subsection{Parameters of developed auxetic structures}

In order to study the influence of different parameters, auxetic structures were produced using different types of core fibres having different linear densities (2400 tex, 4800 tex, and 6000 tex glass fibre; 4800 tex basalt fibre and 4800 tex carbon fibre). Also, structures angle $\varphi\left(66^{\circ}, 72^{\circ}\right.$ and $\left.78^{\circ}\right)$ was varied and its effect on auxetic and tensile behaviour was studied. Moreover, modification of basic structure through addition of straight longitudinal rod and further change in structural angle resulted in different structural parameters, which are listed in Table 2, along with material parameters. The developed structures are presented in Fig. 1.

\subsection{Evaluation of auxetic and tensile behaviours of the structures}

The measurement of Poisson's ratio and tensile properties of the auxetic structures was carried out in a Universal Tensile Testing Machine. The cross-head speed of tensile testing machine was kept at $25 \mathrm{~mm} / \mathrm{min}$. White marks were painted on the structures at top (1/4), middle (1/2) and bottom (3/4) of the structures [18]. During tensile testing, the video of sample deformation with load was captured using Canon EOS 650D and later, the video was converted into images at specific intervals (per second) using image analysis software (ImageJ). The distance between the marks in the structures, both in longitudinal and transverse directions, was measured in pixels using Image software. The longitudinal and transverse strains were then calculated by using the following formulae [18]:

$\epsilon_{x}=\frac{x_{n}-x_{0}}{x_{0}}$

$\epsilon_{y}=\frac{y_{n}-y_{0}}{y_{0}}$

where $x_{n}$ and $y_{n}$ are the distance between the points marked on the structure at $n$th of loading, $x_{0}$ and $y_{0}$ are the original distance between the marks at zero loading. The average transverse strain was calculated by averaging the transverse strain calculated at top, middle and bottom points (1-3, 4-5, and 6-8). Similarly, the average longitudinal strain was calculated from longitudinal strains

Table 2

Parameters of developed auxetic structures.

\begin{tabular}{lllll}
\hline Structure & $\begin{array}{l}\text { Core fibre } \\
\text { type }\end{array}$ & $\begin{array}{l}\text { Core fibre, } \\
\text { tex }\end{array}$ & Angle $\varphi,^{\circ}$ & Rib length, cm \\
\hline S-1 & Glass & 2400 & 66 & $r_{1}-2.70 \& r_{2}-2.35$ \\
S-1 & Glass & 4800 & 66 & $r_{1}-2.70 \& r_{2}-2.35$ \\
S-1 & Glass & 6000 & 66 & $r_{1}-2.70 \& r_{2}-2.35$ \\
S-1 & Glass & 9600 & 66 & $r_{1}-2.70 \& r_{2}-2.35$ \\
S-1 & Glass & 4800 & 72 & $r_{1}-2.60 \& r_{2}-2.35$ \\
S-1 & Glass & 4800 & 78 & $r_{1}-2.50 \& r_{2}-2.35$ \\
S-1 & Basalt & 4800 & 66 & $r_{1}-2.70 \& r_{2}-2.35$ \\
S-1 & Carbon & 4800 & 66 & $r_{1}-2.70 \& r_{2}-2.35$ \\
S-2 & Glass & 4800 & 66 & $r_{1}-2.70 \& r_{2}-2.35$ \\
S-3 & Glass & 4800 & 78 & $r_{1}-2.50 \& r_{2}-2.35$ \\
\hline
\end{tabular}

a $\mathrm{S}-2$ and S-3 consists both undulation and straight longitudinal rods. 
measured from left and right points of the structures (1-6, 2-7, and 3-8). The measurement principle has been illustrated in Fig. 2. Later, the Poisson's ratio was calculated from the average strains by [18],

$v_{x y}=-\frac{\left\langle\epsilon_{x}\right\rangle}{\left\langle\epsilon_{y}\right\rangle}$

\section{Results and discussion}

\subsection{Auxetic behaviour of the structures}

The developed structures based on missing rib or lozenge grid design show negative Poisson's ratio. While tensile load is applied to the structure longitudinally, the angle of longitudinal rods gradually increases, resulting in straightening of these rods until angle $\varphi$ reaches $90^{\circ}$. Straightening of the longitudinal rods leads to opening of the undulated transverse rods through connecting point, i.e. the angle $\alpha$ increases, resulting in transverse expansion of the structures. To explain this point, the change of unit cell at different stages of tensile loading is shown in Fig. 3.

\subsection{Effect of core fibre on auxetic behaviour}

To study the effect of core fibre type, auxetic structures were developed from braided composite rods consisting of glass, basalt, and carbon core fibres with same linear density, 4800 tex. As presented in Fig. 4a and given in Table 3, the core fibre type displays influence on auxetic behaviour and the trend of Poisson's ratio change with longitudinal strain is the same for all the fibres. The value of Poisson's ratio first stays same with certain strain level and decreases with increase of longitudinal strain.

The Poisson's ratio values remain constant until around $\sim 5.5 \%$ longitudinal strain and then start to decrease with additional increase of strain until failure of the structures. The straightening of longitudinal rods stop at this strain level $(\sim 5.5 \%)$, i.e. they become fully straight and no further transverse expansion is possible. Further axial strain after this point, therefore, results in reduction of Poisson's ratio.

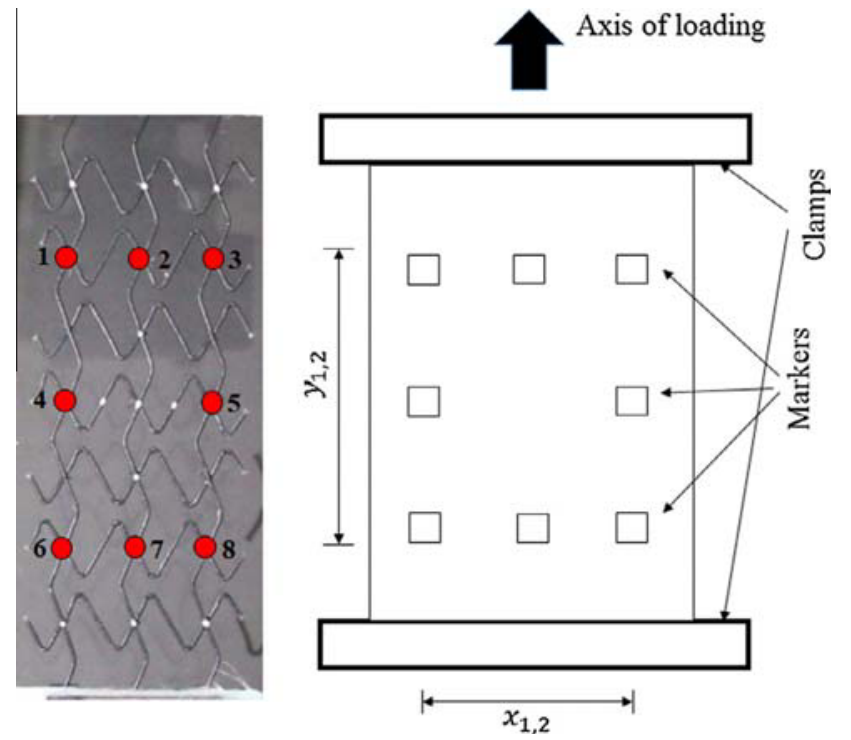

Fig. 2. (a) Auxetic structure with painted marks, and (b) schematic points for strain calculation. (For interpretation of the references to colour in this figure legend, the reader is referred to the web version of this article.)
The maximum negative Poisson's ratio value is observed for glass fibre structure, followed by basalt and carbon fibre structures. Maximum Poisson's ratio obtained with glass fibre was 18\% and 23\% higher as compared to basalt and carbon fibre based structures, respectively. The stiffness of the core fibre strongly influences the auxetic behaviour of the structures. The structures developed from high stiffness fibre (carbon) experience lower deformation, i.e. lower expansion of transverse rods under tensile load resulting in lower Poisson's ratio value. Hence, the developed auxetic structures show Poisson's ratio in the following order, which is just the opposite of the stiffness of core fibres: Poisson's ratio glass structure $>$ Poisson's ratio ${ }_{\text {basalt structure }}>$ Poisson's ratio carbon structure.

\subsection{Effect of linear density of braided composite rods on auxetic behaviour}

The effect of linear density of core fibres (i.e. BCR diameter) on auxetic behaviour of developed structures can be seen from Table 4 and Fig. $4 \mathrm{~b}$. It is obvious from Table 4 that the diameter of BCRs increases with the increase in linear density of core fibre. The change in the BCR diameter causes change in the auxetic behaviour of the structures. An increase in the BCR diameter reduces the auxetic behaviour (4800-6000 tex). This is due to the fact that higher diameter (i.e. high linear density core) longitudinal and transverse elements present more resistance towards deformation, resulting in lower transverse expansion and Poisson's ratio. However, the structures produced using glass fibre with linear density of 2400 tex, exhibit lower Poisson's ratio as compared to 4800 tex glass fibre. This is attributed to the fact that too low linear density of core fibres, i.e. BCR diameter results in highly flexible structures, which are not capable of transmitting the longitudinal strains to the transverse direction, resulting in lower Poisson's ratio. Therefore, there exists an optimum value for the core linear density or BCR diameter, below or above which Poisson's ratio decreases.

\subsection{Effect of structural angle $\varphi$ on auxetic behaviour}

Table 5 and Fig. 4c show the effect of initial structural angle, $\varphi$. It can be observed that an increase in $\varphi$ increases the Poisson's ratio value. Higher angle of the longitudinal inclined rods results in improved tensile load bearing capability and this, in turn, leads to higher deformation in transverse direction and higher Poisson's ratio. Maximum Poisson's ratio obtained with initial structural angle $66^{\circ}$ was $\sim 41 \%$ and $\sim 73 \%$ lower as compared to $72^{\circ}$ and $78^{\circ}$, respectively.

\subsection{Influence of structural modification on auxetic behaviour}

The basic auxetic structure, i.e. missing rib or lozenge grid or cross-chiral design has been modified with longitudinal straight rods to enhance their strengthening behaviour (especially at lower strain level), so that auxetic structures will be suitable for strengthening of structural elements. The auxetic behaviour of the modified structures is shown in Fig. 5. Even though the modified structure consists of straight longitudinal rod, it exhibits negative Poisson's ratio, but the Poisson's ratio value is considerably lower as compared to the basic structure (structure-1). The straight longitudinal rods restrict the structural deformation and transverse expansion of the structure leading to lower Poisson's ratio. Poisson's ratio remains high at very low strain and then drops, and again starts to increase until 3\% strain value, after which Poisson's ratio remains constant until $\sim 6 \%$ strain and decreases again sharply until the failure of the structures. This type of trend is due to the complex structural deformation due to the presence of the straight rods which break at around 3\% axial strain value (see Fig. 5). 


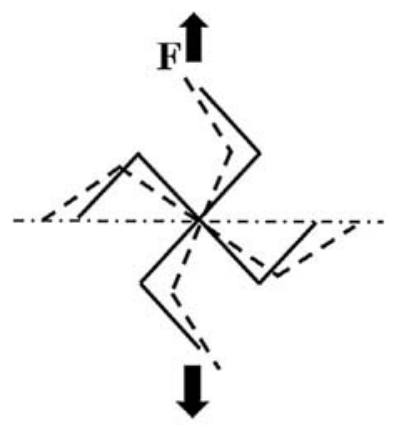

(a)

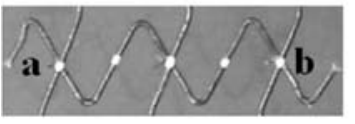

Distance between $a-b=10.15 \mathrm{~cm}$

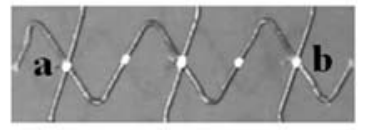

Distance between $\mathrm{a}-\mathrm{b}=10.55 \mathrm{~cm}$

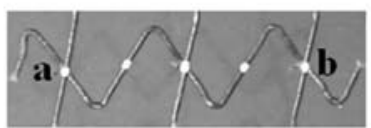

Distance between $a-b=11.05 \mathrm{~cm}$

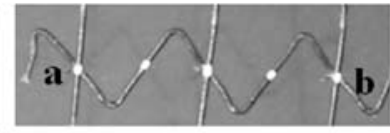

Distance between $a-b=11.55 \mathrm{~cm}$

(b)

Fig. 3. Unit cell of structure-1. (a) Schematic diagram of force acting and displacement of unit cell, and (b) displacement of unit cell (real structure-1) at different stages of loading.

The initial structural angle $\varphi$ of the longitudinal rod of structure- 2 is $66^{\circ}$. This angle is increased to $78^{\circ}$ in structure- 3 to enhance their strengthening capability. The auxetic behaviour of this structure is shown in Fig. 5. Poisson's ratio of structure-3 is significantly higher as compared to structure-2 and decreases with increase in longitudinal strain. The higher Poisson's ratio is due to the higher initial angle of longitudinal inclined rods.

\subsection{Tensile properties of auxetic structures}

The tensile properties of auxetic structures-1, (produced by varying type of fibre, linear density, and varying angle $\varphi$ ) structure- 2 and 3 are provided in Table 6 . The tensile load is the highest for carbon, followed by basalt and glass. Higher tensile load obtained in case of carbon fibre based structures is due to higher stiffness of carbon fibres. Similarly, basalt fibres have higher tensile properties as compared to glass fibres resulting in higher tensile load in basalt based structures. The typical tensile behaviour of the developed auxetic structures is shown in Fig. 6.

Table 6 also shows that the increase in linear density of core fibre increases the tensile load and decreases elongation (\%) value. This is due to the fact that the increase in linear density (6000 tex) increases the no. of filaments in BCR cross section and improves the load bearing capacity of the structures. It can also be noted from Table 6 that increase in initial structural angle $(\varphi)$ increases the tensile load of the structures. With higher initial angle $\varphi$ $\left(78^{\circ}\right)$, the longitudinal inclined rods become straight quickly and starts bearing higher load as compared to the inclined rods with lower initial angle $\varphi\left(66^{\circ}\right)$.

\subsection{Failure mode of auxetic structures}

The failure modes of the developed auxetic structures are shown in Fig. 7. The weakest points in these auxetic structures are the linking points or ribs bases. Therefore, during loading, stress concentration occurred in these points leading to failure of the structures (shown by arrows in Fig. 7a). In the modified structures with straight rods (structure-2, and 3), in the initial period, load was mainly taken by the straight rods. So, in this period they are subjected much higher stresses as compared to the bent rods (shown by arrows in Fig. 7b). So, failure first occurred in the straight rods and after the breakage of the straight rods, load was fully transferred to the bent elements resulting in their straightening, stretching and finally failure at the weak points (shown by arrow in Fig. 7c).

The fracture surface of the braided rods is presented in Fig. 8. It shows the broken glass fibres in the core region surrounded by the outer polyester fibres. At high magnification it is evident that both polyester and glass fibres were impregnated by the resin. The brittle fracture of glass fibres and the ductile failure of polyester cover fibres can also be clearly noticed from the fracture surface.

\subsection{Work of rupture of the developed auxetic structures}

Work of rupture (WOR) or energy required to break the structures has been calculated using load-elongation curve of the structures. Work of rupture $(\mathrm{J})$ calculated for the developed auxetic structures are given in Table 6. As expected, the work of rupture of structure- 1 increases with the increase in the linear density of glass fibre and structural angle $\varphi$. The work of rupture of the structures developed from different core fibres lies in the following

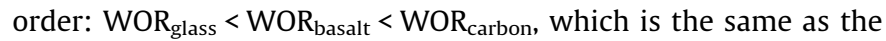
tensile load bearing capacity of the structures. Work of rupture for different structures developed from glass fibre lies in the order: $W \mathrm{R}_{\text {structure-1 }}<\mathrm{WOR}_{\text {structure-2 }}<\mathrm{WOR}_{\text {structure-3, which also follows }}$ the same order as the tensile performance of the structures. As structure-3 exhibits higher work of rupture and better tensile property than other structures as well as moderate auxetic behaviour, it can be proposed for the structural applications.

\section{Analytical model}

\subsection{Analytical model for structure-1}

The analytical model which was used in our previous work [2] showed large difference between the experimental and analytical results and the previous model has been revised in the present work considering the real deformational modes of the structures. In the previous analytical model, angles $\zeta$ and $\varphi$ were considered to be related with each other and both with respect to the vertical undulation rods. In other words, it was assumed that the longitudinal and transverse strains are dependent on the stiffness of $\zeta$ 

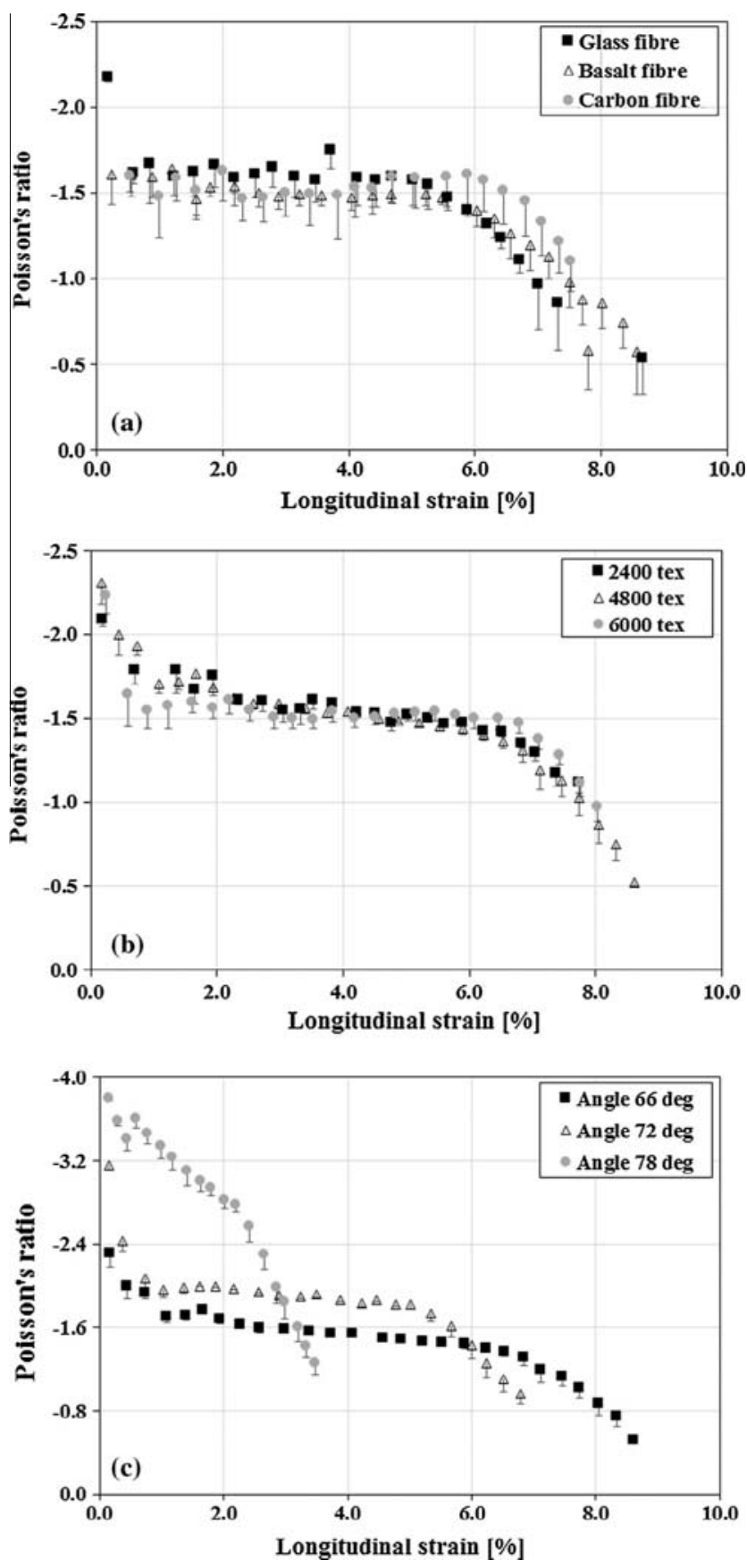

Fig. 4. Auxetic behaviour of developed structures. (a) Effect of core fibre type, (b) effect of core fibre linear density, and (c) effect of structure's initial angle $(\varphi)$.

Table 3

Poisson's ratio of the auxetic structures developed from various core fibres.

\begin{tabular}{lllll}
\hline $\begin{array}{l}\text { Core } \\
\text { fibre } \\
\text { (tex) }\end{array}$ & $\begin{array}{l}\text { Type } \\
\text { of fibre }\end{array}$ & $\begin{array}{l}\text { Average } \\
\text { diameter of } \\
\text { BCR }(\mathrm{mm})\end{array}$ & $\begin{array}{l}\text { Average max. } \\
\text { Poisson's } \\
\text { ratio }\end{array}$ & $\begin{array}{l}\text { Percentage of change in } \\
\text { Poisson's ratio w.r.t } \\
\text { glass }\end{array}$ \\
\hline 4800 & Glass & $2.4(2.1)$ & $-2.2(4.0)$ & - \\
4800 & Basalt & $2.4(3.4)$ & $-1.8(8.3)$ & $\downarrow 18.2$ \\
4800 & Carbon & $2.1(4.0)$ & $-1.7(14.3)$ & $\downarrow 22.7$
\end{tabular}

and $\varphi$, hinges, respectively. Meanwhile the deformation (and thus stiffness) of $\zeta$, is related to $\varphi$. However, from the deformation of the structure during testing (Fig. 3), it seems that although a hinging mechanism formula can be suitable for the structure, the opening
Table 4

Poisson's ratio of auxetic structures produced from glass fibres with different linear densities.

\begin{tabular}{llll}
\hline $\begin{array}{l}\text { Glass } \\
\text { fibre } \\
\text { tex })\end{array}$ & $\begin{array}{l}\text { Average } \\
\text { diameter } \\
(\mathrm{mm})\end{array}$ & $\begin{array}{l}\text { Average max. } \\
\text { Poisson's ratio }\end{array}$ & $\begin{array}{l}\text { Percentage of change in } \\
\text { Poisson's ratio w.r.t 2400 tex }\end{array}$ \\
\hline 2400 & $2.1(3.9)$ & $-2.1(3.7)$ & - \\
4800 & $2.4(2.1)$ & $-2.2(4.0)$ & $\uparrow 4.8$ \\
6000 & $2.7(2.4)$ & $-1.9(6.7)$ & $\downarrow 9.5$ \\
\hline
\end{tabular}

Note: the values in the bracket are CV\%.

Table 5

Auxetic behaviour of structures having different initial angle $\varphi$.

\begin{tabular}{lllll}
\hline $\begin{array}{l}\text { Glass } \\
\text { fibre } \\
\text { (tex) }\end{array}$ & $\begin{array}{l}\text { Initial } \\
\text { angle } \varphi \\
\left({ }^{\circ}\right)\end{array}$ & $\begin{array}{l}\text { Average max. } \\
\text { Poisson's ratio }\end{array}$ & $\begin{array}{l}\text { CV } \\
\%\end{array}$ & $\begin{array}{l}\text { Percentage of change in } \\
\text { Poisson's ratio w.r.t } 66^{\circ}\end{array}$ \\
\hline 4800 & 66 & -2.2 & 4.0 & - \\
4800 & 72 & -3.1 & 2.5 & $\uparrow 40.9$ \\
4800 & 78 & -3.8 & 1.2 & $\uparrow 72.7$ \\
\hline
\end{tabular}

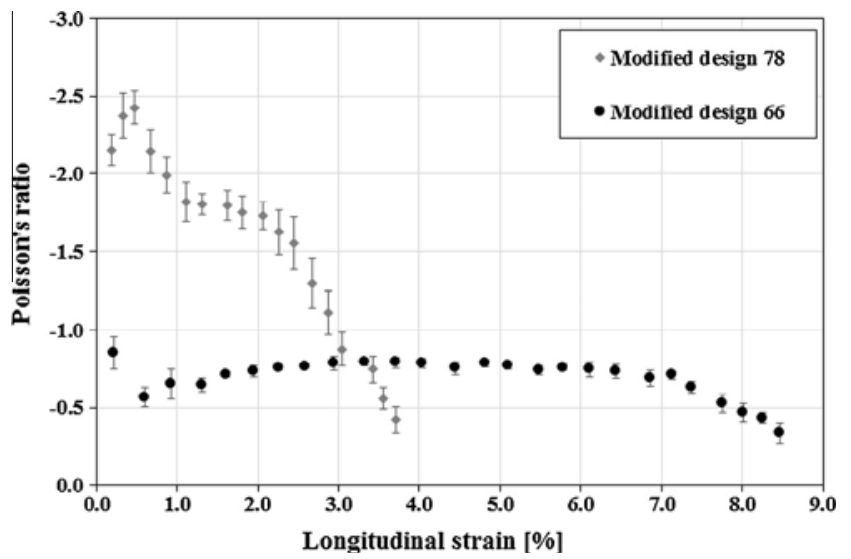

Fig. 5. Auxetic behaviour of structure- 2 and structure- 3 produced from glass fibre reinforced BCRs.

Table 6

Tensile properties of developed auxetic structures.

\begin{tabular}{|c|c|c|c|c|c|c|}
\hline Structure & $\begin{array}{l}\text { Fibre } \\
\text { type }\end{array}$ & Tex & $\begin{array}{l}\text { Angle } \\
\varphi\left({ }^{\circ}\right)\end{array}$ & $\begin{array}{l}\text { Avg. max. } \\
\text { tensile } \\
\text { load }(\mathrm{kN})\end{array}$ & $\begin{array}{l}\text { Avg. } \\
\text { elongation at } \\
\text { max. tensile } \\
\text { load }(\%)\end{array}$ & $\begin{array}{l}\text { Avg. } \\
\text { work of } \\
\text { rupture } \\
\text { (J) }\end{array}$ \\
\hline S-1 & Glass & 2400 & 66 & $4.2(10.6)$ & $10.0(4.1)$ & $\begin{array}{l}35.2 \\
(12.0)\end{array}$ \\
\hline S-1 & Glass & 4800 & 66 & $4.9(15.2)$ & $9.3(6.3)$ & $\begin{array}{l}38.2 \\
(2.7)\end{array}$ \\
\hline S-1 & Glass & 6000 & 66 & $5.9(10.5)$ & $9.1(2.2)$ & $\begin{array}{l}49.2 \\
(5.0)\end{array}$ \\
\hline S-1 & Glass & 4800 & 72 & $5.1(12.7)$ & $7.2(6.5)$ & $\begin{array}{l}42.9 \\
(6.0)\end{array}$ \\
\hline S-1 & Glass & 4800 & 78 & $6.9(10.1)$ & 4.3 (9.7) & $\begin{array}{l}47.8 \\
(8.7)\end{array}$ \\
\hline S-1 & Basalt & 4800 & 66 & $6.1(14.7)$ & 9.5 (1.9) & $\begin{array}{l}45.7 \\
(14.5)\end{array}$ \\
\hline S-1 & Carbon & 4800 & 66 & $7.3(15.5)$ & $8.7(5.6)$ & $\begin{array}{l}71.3 \\
(12.4)\end{array}$ \\
\hline S-2 & Glass & 4800 & 66 & $3.4(11.2)$ & $8.9(5.0)$ & $\begin{array}{l}43.7 \\
(10.5)\end{array}$ \\
\hline$S-3$ & Glass & 4800 & 78 & $5.5(8.3)$ & $3.0(7.9)$ & $\begin{array}{l}48.8 \\
(6.1)\end{array}$ \\
\hline
\end{tabular}

Note: values in the bracket are CV\% 


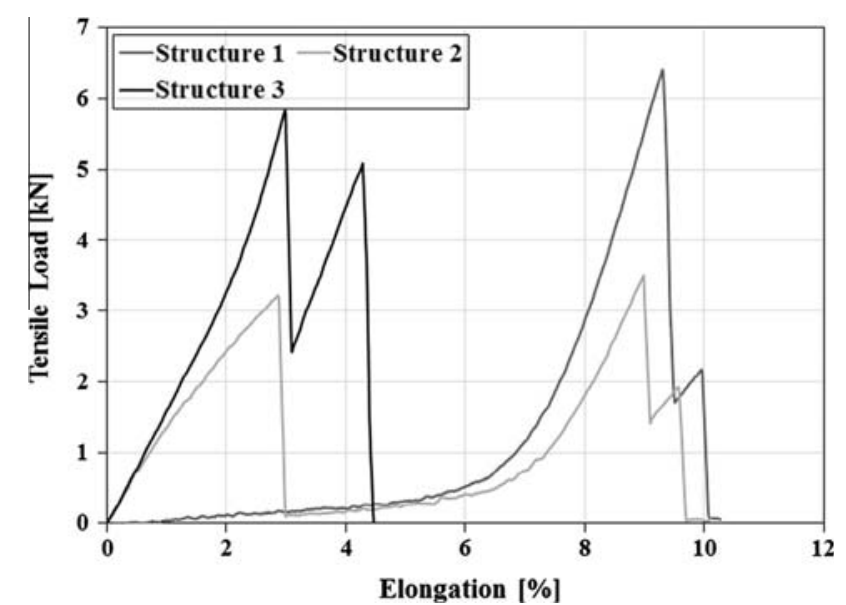

Fig. 6. Tensile behaviour of developed auxetic structures.

of horizontal undulation rods (stiffness of angle $\alpha$, Fig. 1a) governs that structure's transverse expansion and thus the equations should be modified based on this mechanism. In this case, the longitudinal strain $\left(\boldsymbol{\epsilon}_{\boldsymbol{y}}\right)$, the transverse strain $\left(\boldsymbol{\epsilon}_{\boldsymbol{x}}\right)$ can be expressed as follows:

$\epsilon_{x}=\left(\frac{\sin \alpha_{n}}{\sin \alpha_{0}}-1\right)$

$\epsilon_{y}=\left(\frac{\sin \varphi_{n}}{\sin \varphi_{0}}-1\right)$

$v_{x y}=-\frac{\epsilon_{x}}{\epsilon_{y}}$

Fig. 9 shows that the angle $\alpha$ can be presented as a function of angle $\varphi$ based on the obtained experimental results as:

$\alpha=0.948 \varphi-6.82$

Using Eq. (7), the angle $\alpha$ is calculated with respect to varying angle $\varphi$ periodically from the initial angle $\left(\varphi-66^{\circ}\right)$. By using angle $\alpha$ and $\varphi$ the transverse strain and longitudinal strain were calculated (using
Eqs. (4) and (5)) and the Poisson's ratio was obtained using Eq. (6). Fig. 10 shows Poisson's ratio of structure- 1 calculated from revised analytical model and compared with experimental results. The results show that the Poisson's ratio calculated from the revised analytical model is well fitted with experimental results. However, it is observed that after around 6\% longitudinal strain the analytical Poisson's ratio increases in contrary to the experimental results. This is due to the fact that after a certain opening of hinges (or longitudinal strain), the stretching mechanism becomes the governing behaviour and the hinging mechanism cannot produce accurate predictions. Activation of the stretching mechanism leads to reduction of Poisson's ratio as it can be observed in the experimental results. As the developed analytical model does not consider this phenomenon, the predicted results diverge from the experimental observations after $6 \%$ longitudinal strain.

\subsection{Analytical model for structure-2 and 3}

The experimental results show hinging mechanism is still suitable for simulating the deformation of the modified design of missing rib or lozenge grid or cross-chiral (structures-2 and 3). Eq. (5) can be used to calculate longitudinal strain as a function of angle $\varphi$. However, Eq. (4) needs to be revised as the unit cell is different in these structures.

Here, structure's width is selected as the unit cell as shown in Fig. 11. Therefore, the transverse deformation of the structures become dependent on the angles $\alpha$ and $\beta$. However, analysis of the experimental results showed the transverse deformation mainly occurs due to the changes of angle $\alpha$ as angle $\beta$ does not significantly change during tests due to the effect of vertical straight rod. Fig. 12, presenting the relation between angle $\varphi$ vs angle $\alpha$ and angle $\beta$, clearly presents this observation. (All the angles $\varphi, \alpha$, and $\beta$ are measured from the images taken during tensile loading.) Assuming that the transverse deformation is only dependent on angle $\alpha$, the change of transverse length can be written as $\Delta l=4 r_{2}\left[\sin \left(\frac{\alpha_{n}}{2}\right)-\sin \left(\frac{\alpha_{0}}{2}\right)\right]$. The transverse strain can thus be obtained as follows:

$$
\varepsilon_{T}=\frac{\Delta l}{l}=\frac{4 r_{2}\left[\sin \left(\frac{\alpha_{n}}{2}\right)-\sin \left(\frac{\alpha_{0}}{2}\right)\right]}{l}
$$

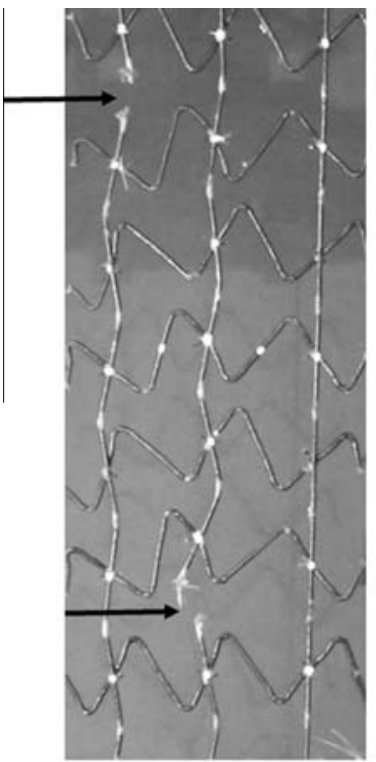

(a)

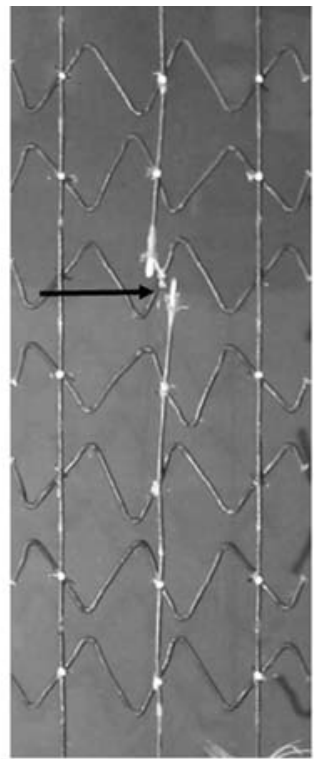

(b)

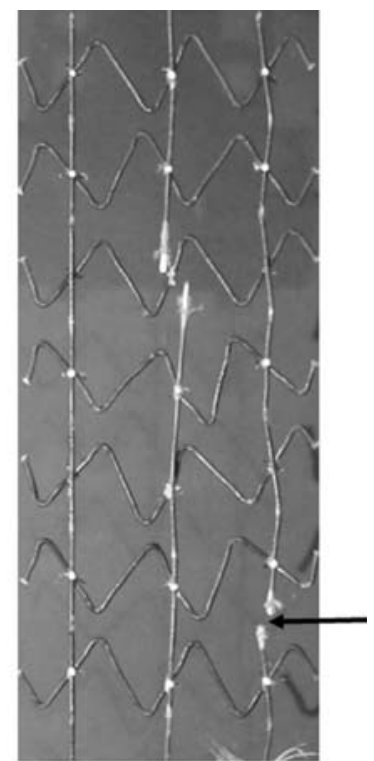

(c)

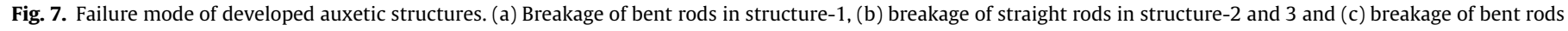
in structure- 2 and 3. 

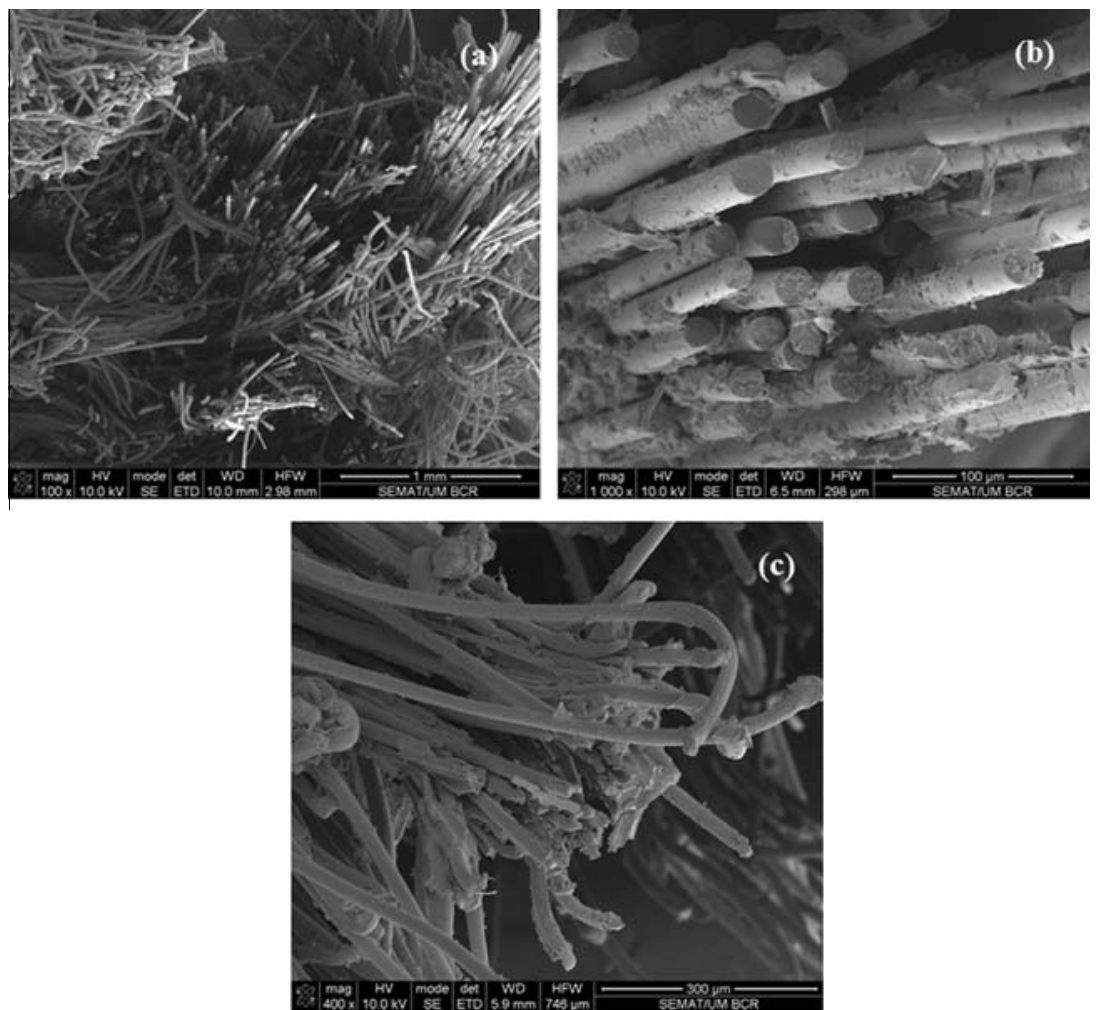

Fig. 8. (a) Fracture surface of braided rods showing overall fracture morphology, (b) axial glass fibre bundles and (c) outer polyester fibres.

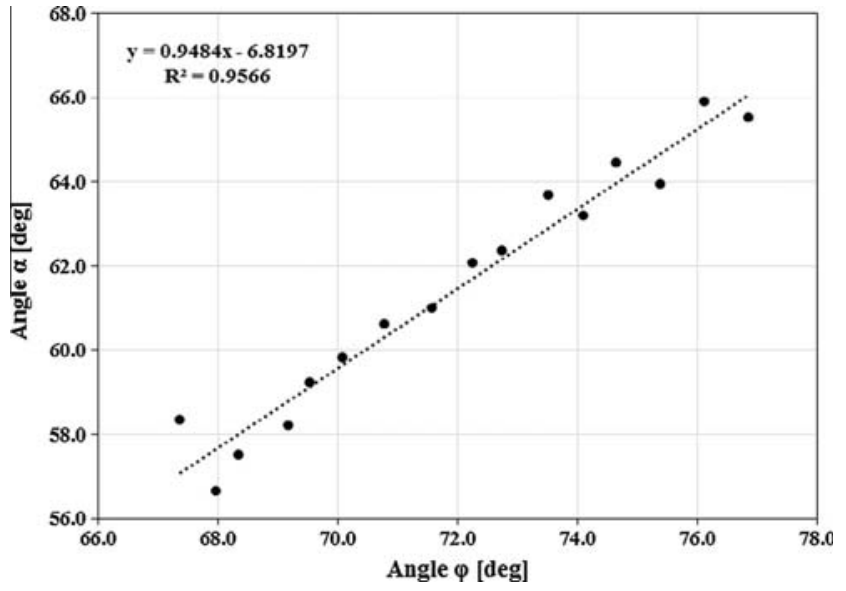

Fig. 9. Relationship between angle $\varphi$ and angle $\alpha$.

Fig. 12 shows that the angle $\alpha$ can be presented as a function of angle $\varphi$ based on the obtained experimental results:

$\alpha=0.9622 \varphi-7.5212$

Using Eq. (9), the angle $\alpha$ is calculated with respect to varying angle $\varphi$ periodically from the initial angle $\left(\varphi-66^{\circ}\right)$. By using angle $\alpha$ and $\varphi$ the transverse strain and longitudinal strain were calculated from Eqs. (5) and (8) and the Poisson's ratio was obtained using Eq. (6).

The analytical Poisson's ratio of structure- 2 is compared with its experimental results in Fig. 13. The results show the analytical Poisson's ratio is similar to experimental ones until a longitudinal strain of about $4.5 \%$. There is a slight difference in the Poisson's ratio at higher longitudinal strains, as the previous structure, which may be due to the assumptions considered in the analytical model, i.e. the structures deforms freely in the transverse direction which does not occur in this case as well due to the clamping system.

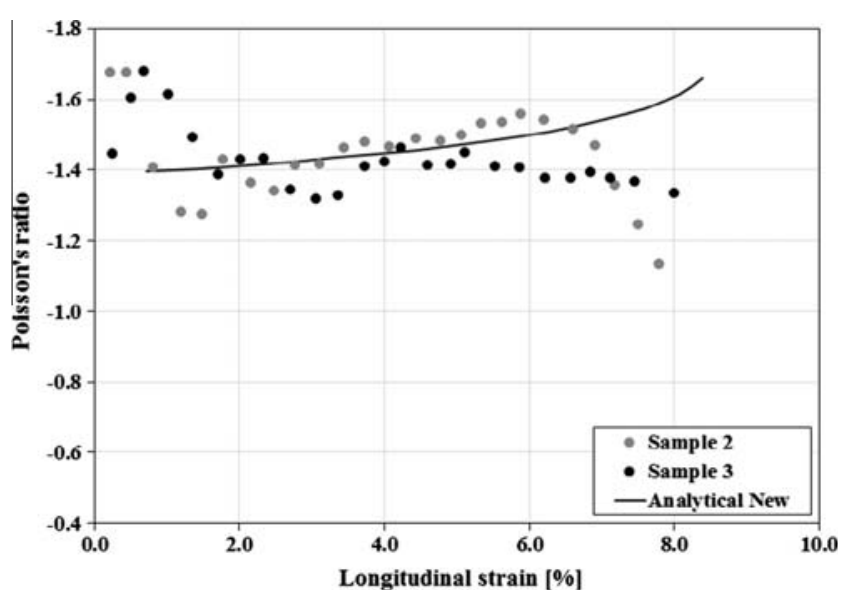

Fig. 10. Poisson's ratio of structure-1: analytical vs. experimental.

\section{Finite element modelling}

\subsection{Modelling strategy}

A two dimensional model is produced in FE code DIANA to simulate the tensile response of the developed auxetic structures. According to the experimental results, the braided composites used for preparation of the specimens have a linear elastic behaviour until failure. The observed nonlinear force-displacement response and auxetic behaviour of the structures are due to the large structural deformation at the ribs' bases and geometric nonlinearity of the system.

The FE model is produced based on the geometry of the tested structures. A simple modelling strategy is adopted using linear three-node beam elements (labeled as L7BEN in DIANA) to 


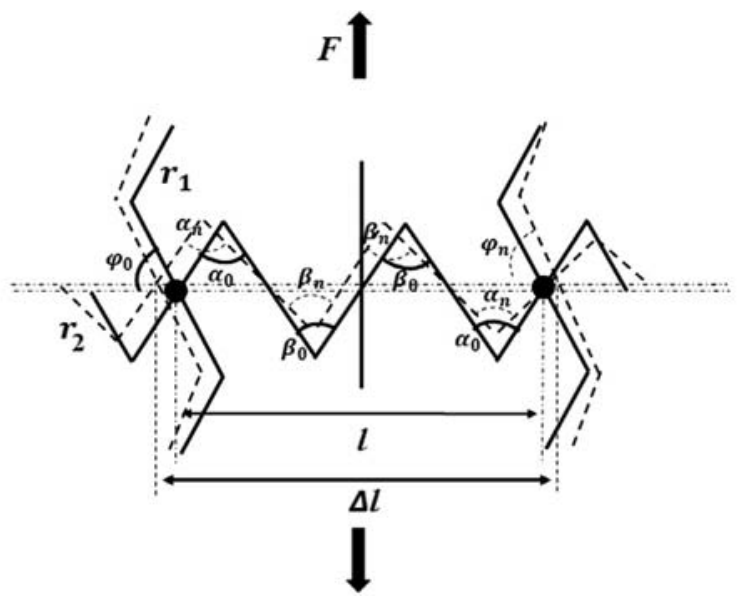

(a)

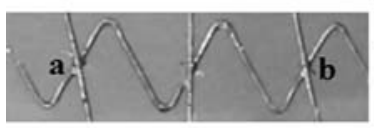

Distance between $a-b=9.96 \mathrm{~cm}$

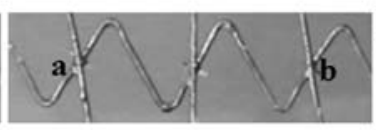

Distance between $a-b=10.09 \mathrm{~cm}$

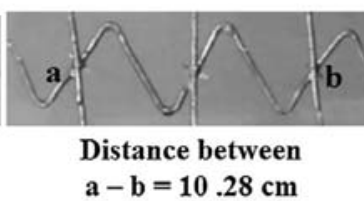

$a-b=10.28 \mathrm{~cm}$

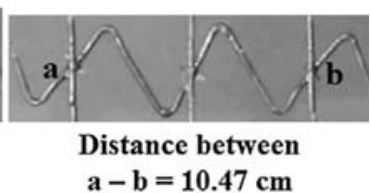

$a-b=10.47 \mathrm{~cm}$

(b)

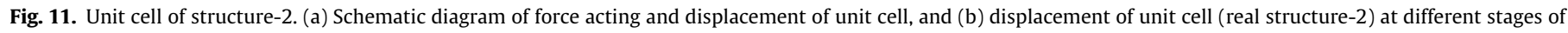
loading. ( $\alpha$ and $\beta$ - angles formed at the bending of horizontal undulation rod nearer to the vertical undulation rods and nearer to the vertical straight rod, respectively.)

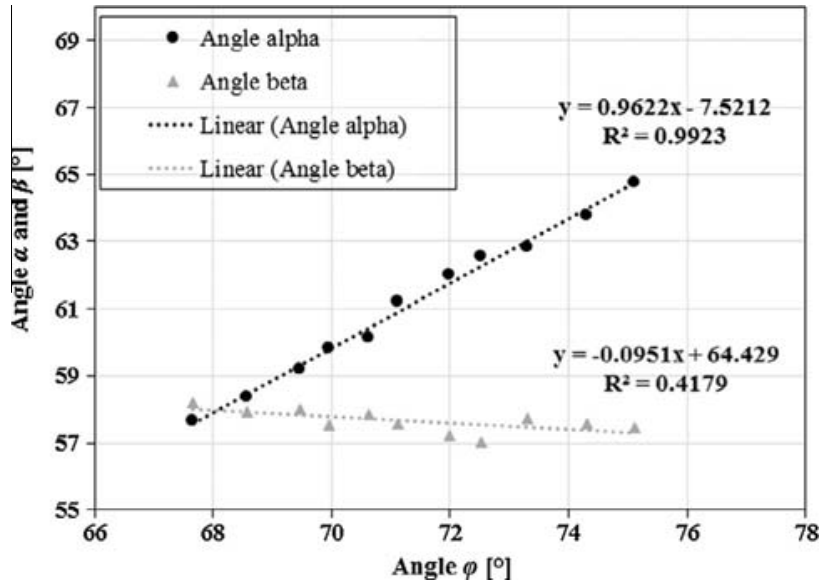

Fig. 12. Relation between angle $\varphi$ vs angle $\alpha$ and $\beta$.

represent the ribs and linear rotational spring elements (labeled as SP2RO in DIANA) for simulating the ribs rotational stiffness at the curvature points, see Fig. 14. The beams have a circular cross section with diameter of $D=2.39 \mathrm{~mm}$ according to the experimental measurements. The intersection of the vertical and the horizontal joints are modelled with continuous elements without introducing any extra degree of freedom. The constraints and loading conditions are applied to the model as the experimental tests were performed, i.e. the displacements of the structure at both ends are constrained in both $x$ and $y$ directions. An incremental monotonic displacement load is applied to one side of the model for simulating the tensile test conditions.

A linear elastic with brittle failure material model and a linear elastic rotational spring are used for the ribs and the springs, respectively. The elastic modulus, $E$, of rods was taken $14.2 \mathrm{GPa}$ according to the experimental results. Due to the lack of sufficient information, the properties of rotational springs are obtained by performing a parametric analysis as explained in Section 5.2.

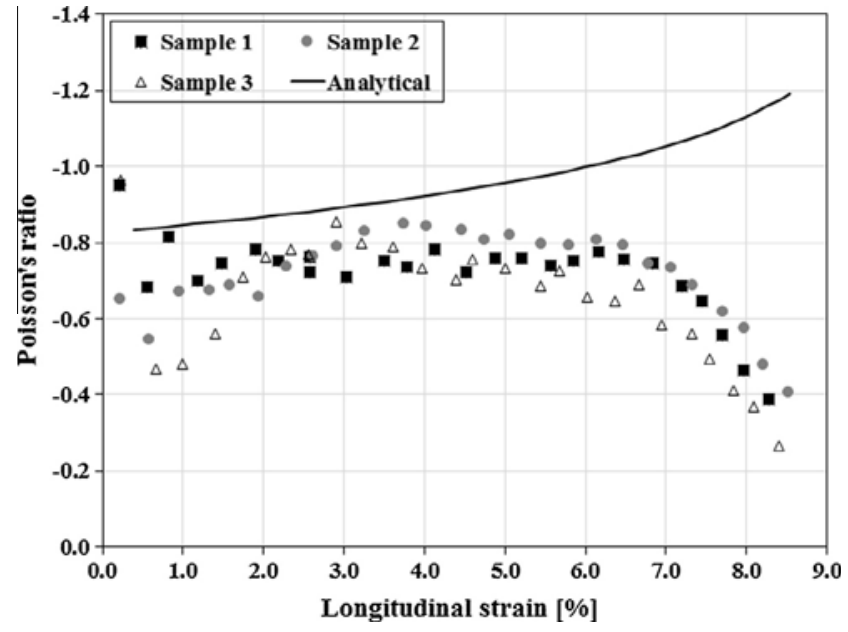

Fig. 13. Poisson's ratio of structure-2: analytical vs. experimental.

A geometric nonlinear analysis with total Lagrange formulation is performed to simulate the large deformation and auxetic behaviour of the structures. The total Lagrange formulation is useful when rotations and displacements are large and strains are small as is the case of the structures under study.

As explained before, the force-displacement response of original auxetic structures (e.g. structure-1) consisted of two main phases. In the initial phase, the response was governed by large deformation and low load resistance. After a certain deformation level, in the second phase, the structure resisted higher loads with lower deformation capacity. Different solution strategies deemed necessary for numerically simulating of the structural response in each phase. A modified Newton-Raphson iterative scheme together with the line search method and displacement convergence criteria are used for solving the nonlinear equations in the initial phase of structural behaviour. The analysis is then contin- 


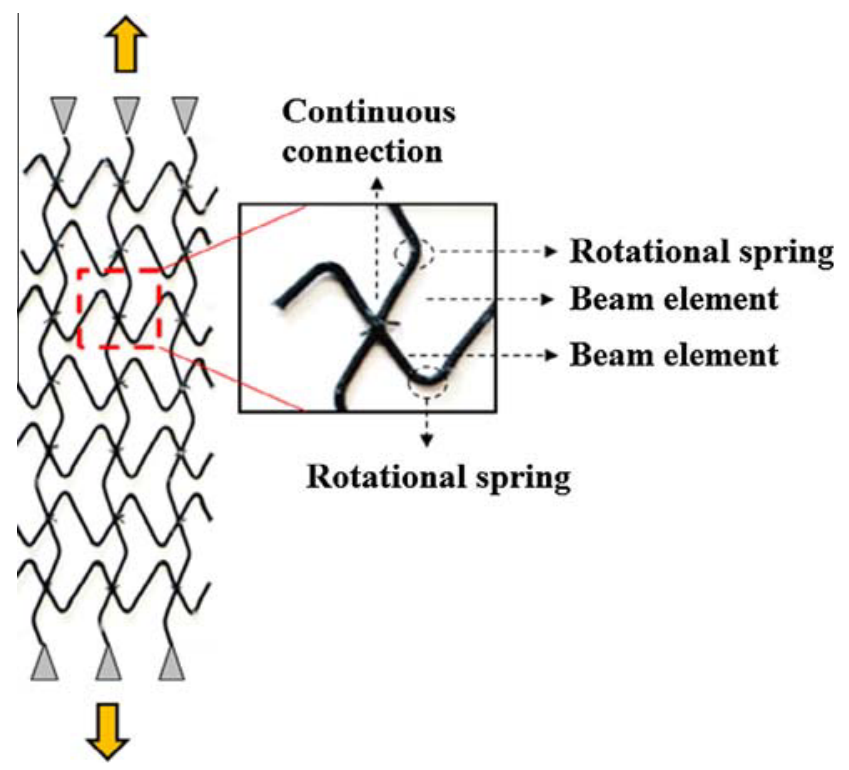

Fig. 14. FE modelling strategy. (For interpretation of the references to colour in this figure legend, the reader is referred to the web version of this article.)

ued, in the second phase, with a quasi-Newton iterative method and force (or energy) convergence criteria. On the other hand, the behaviour of modified structures (e.g. Structure-2) generally consisted of three phases initiating with a linear elastic behaviour until the failure of the straight rods. Then, the load dropped significantly by entering the second phase which was similar to the first phase behaviour of original structures (large deformation and low load resistance) followed by the third phase (small deformation and high load resistance). A similar solution strategy as the original structures was adopted for each phase of the analysis to ease the convergence of the numerical problem.

\subsection{Springs' properties validation}

A numerical back analysis was performed for estimating the rotational stiffness of the springs. For this reason, tensile tests were performed on two type of specimens each consisting of five straight rods and four curvature points, see Fig. 15a. The specimens were prepared with different connection angles of $19^{\circ}$ and $29^{\circ}$ (three specimens for each angle).

The numerical analysis was then performed to simulate the experimental tensile behaviour of each specimen type following the same modelling strategy as explained in Section 5.1. Having the elastic modulus of the rods, a parametric study was performed on the stiffness of the rotational springs for obtaining the best simulation of experimental results. It was observed that a rotational stiffness of $k=1000 \mathrm{~N} \mathrm{~mm} / \mathrm{rad}$ leads to an acceptable prediction of the experimental behaviour in both specimen types, see Fig. 15b. This rotational stiffness is thus used in further simulations.

\subsection{FE modelling results}

The same modelling strategy and material models presented in Section 5.1 are used for simulating the observed experimental behaviour of developed auxetic structures presented in Fig. 1(a \& d). The main focus is on prediction of the force-displacement behaviour and the changes of the Poisson's ratio during the tests. The numerical results are presented in Fig. $16 \mathrm{a}-\mathrm{d}$ in comparison to the experimental observations. It can be seen that the numerical
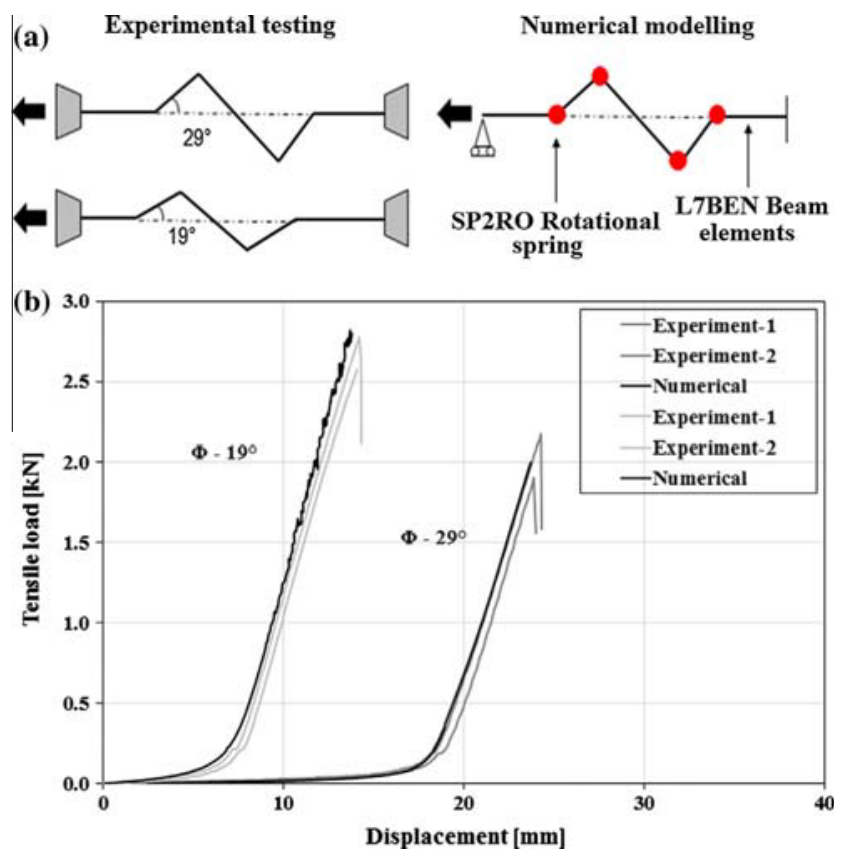

Fig. 15. (a) Validation of the mechanical properties for rotational springs and (b) comparison of experimental and numerical results for single rod tests. (For interpretation of the references to colour in this figure legend, the reader is referred to the web version of this article.)

predictions are in good agreement with experimental results in both prediction of the load-displacement response and Poisson's ratio. The changes of the Poisson's ratio have some differences with the experimental results and this difference is in acceptable range and can be attributed to the imperfections of the handmade specimens and simplified assumptions of the numerical model. In general, the developed numerical model, although being simple, suitably predicted the global response and local deformation of different auxetic structures, being the evidence of applicability of this modelling strategy for predictive purposes or simulating the behaviour of auxetic structures at the structural level.

\section{Summary and conclusions}

In this research, auxetic structures were developed from glass, basalt and carbon fibre reinforced braided rods, and their auxetic and tensile behaviours were studied. A simple image analysis technique was used to measure the strain components of the structures due to tensile loading, and accordingly, Poisson's ratio was calculated. All structures exhibited negative Poisson's ratio and Poisson's ratio was strongly dependent on the initial value of structural angle $(\varphi)$. Poisson's ratio was found to increase with the increase in the initial angle $\varphi$. Also, Poisson's ratio of the structures varied significantly with the change in the core fibres such as carbon, basalt and glass as well as with the braided rod diameter (which depends on the linear density of core fibres). The structure consisting of high stiffness fibre exhibited lower Poisson's ratio as compared to those with lower stiffness fibres. Moreover, the structures with lower braided rod diameter showed higher Poisson's ratio except rods with too low linear density core fibres (2400 tex). The modified auxetic structures (structure-2 and 3) exhibited lower Poisson's ratio than the basic structures due to the restriction in structural movement by the straight elements.

The work of rupture and tensile behaviour of the structures were also observed to depend significantly on the structure angle, braided rod diameter and type of fibre. Higher work of rupture and 

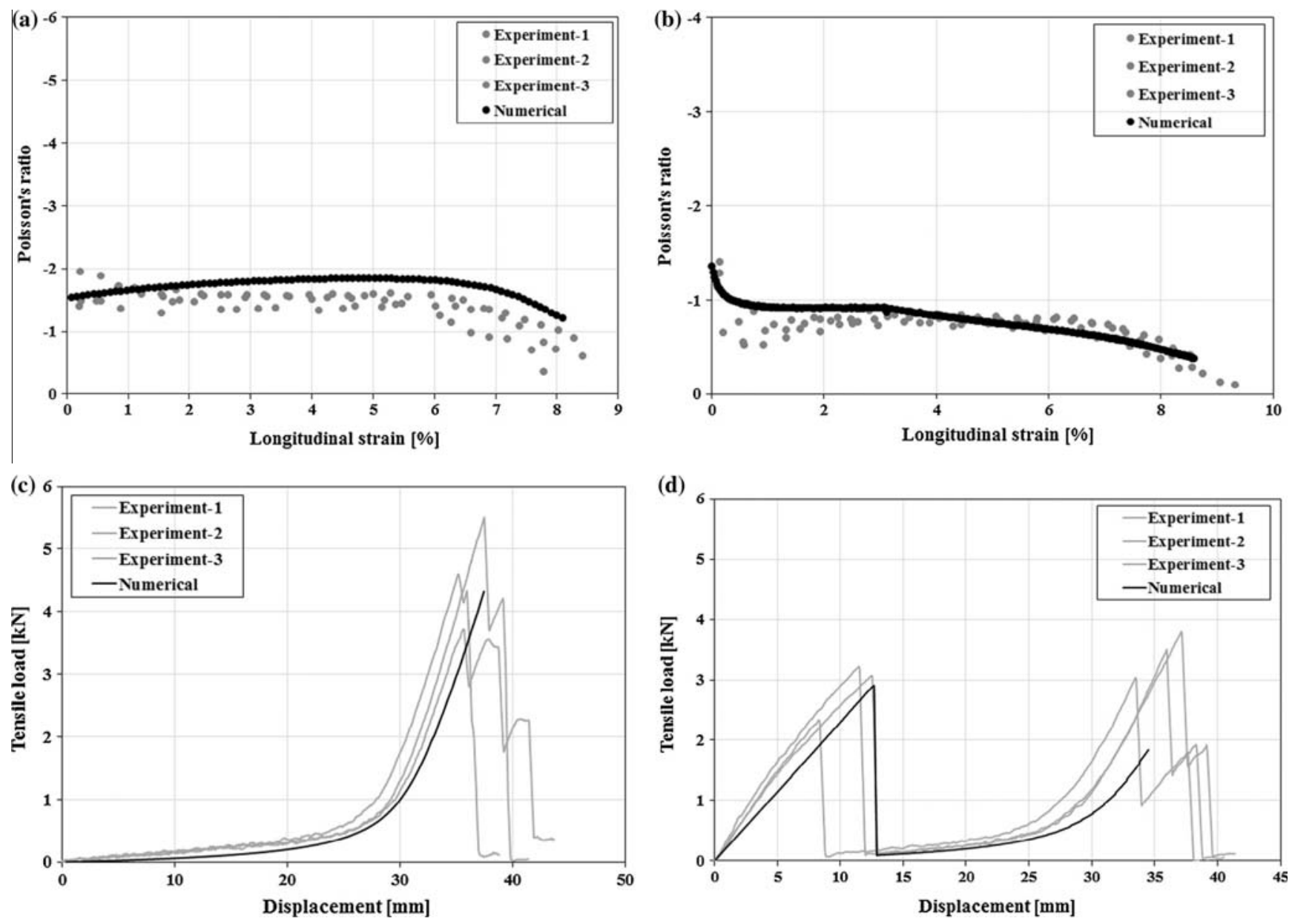

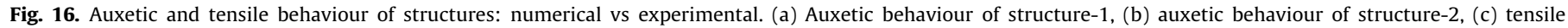
behaviour of structure- 1 and (d) tensile behaviour of structure- 2 .

tensile behaviour were observed for the structures with higher angle, higher rod diameter and high stiffness fibre (e.g. carbon fibre). The work of rupture and tensile behaviour were also enhanced by modifying the structures with straight longitudinal rods (structure-2 and structure-3).

The new analytical model proposed in this research could well predict Poisson's ratio of the basic as well as modified structures, except at very low and high strain levels. Also, the auxetic and tensile behaviour of the developed structures could be well predicted using FE based numerical modelling. It can concluded that the modified auxetic structures developed in this research can have good application possibility for strengthening of civil engineering structures such as concrete elements and masonry walls to resist impact, explosion and seismic loading due to their ductile behaviour and higher energy absorption capability as well as due to possibility to design these structures with the developed modelling techniques.

\section{Acknowledgement}

The authors gratefully acknowledge the financial support for carrying out this research work from University of Minho UMINHO/BI/146/2012, under the scheme of "Strategic plan of school of engineering - Agenda 2020: Multidisciplinary projects."

\section{References}

[1] Smardzewski J, Klos R, Fabisiak B. Design of small auxetic springs for furniture. Mater Des 2013;51:723-8.
[2] Subramani P, Rana S, Oliveira DV, Fangueiro R, Xavier J. Development of novel auxetic structures from braided composites. Mater Des 2014;61:286-95.

[3] Alderson A, Rasburn J, Ameer-Beg S, Mullarkey BG, Perrie W, Evans KE. An auxetic filter: a tuneable filter displaying enhanced size selectivity or defouling properties. Ind Eng Chem Res 2000;39:654-65.

[4] Scarpa F, Smith C, Chambers B, Burriesci G. Mechanical and electromagnetic behaviour of auxetic honeycomb structures. Aeronaut J 2003:175-83.

[5] Alderson A, Rasburn J, Evans KE. Mass transport properties of auxetic (negative Poisson's ratio) foams. Phys Status Solidi (B) 2007;244(3):817-27.

[6] Liu Y, Hu H. A review on auxetic structures and polymeric materials. Sci Res Essays 2010;5(10):1052-63.

[7] Hu H, Wang Z, Liu S. Development of auxetic fabric using flat knitting technology. Text Res J 2011;81(14):1493-502.

[8] Ugbolue SC, Kim YK, Warner SB, Fan Q Yang CL, Kyzymchuk O, et al. Engineering warp knit auxetic fabrics. J Text Sci Eng 2012;2(1):1-8.

[9] Sanami M, Ravirala N, Alderson K, Alderson A. Auxetic materials for sports applications. Procedia Eng 2014;72:453-8.

[10] Evans KE, Anderson KL. Auxetic materials: the positive side of being negative. Eng Sci Educ J 2000:148-54.

[11] Bhullar SK. Three decades of auxetic polymers: a review. e-Polymers 2015;15 (4):205-15.

[12] Kortur C, Liebold-Ribeiro Y. A synthetic approach to identify cellular auxetic materials. Smart Mater Struct 2015;24:1-10.

[13] Yao YT, Uzun M, Patel I. Working of auxetic nano-materials. J Achieve Mater Manuf Eng 2011;49(2):585-93.

[14] Fozdar DY, Soman P, Lee JW, Han LH, Chen S. Three dimensional polymer constructs exhibiting a tuneable negative Poisson's ratio. Adv Funct Mater 2011;21:2712-20.

[15] Darja R, Tatjana R, Alenka PC. Review auxetic textiles. Acta Chim Slov 2013;60:715-23.

[16] Ali I, Jun YJ. Mathematical models for in-plane moduli of honeycomb structures - a review. Res J Appl Sci Eng Technol 2014;7(3):581-92.

[17] Smith CW, Grima JN, Evans KE. A novel mechanism for generating auxetic behaviour in reticulated foams: missing rib foam model. Acta Mater 2000;48:4349-56.

[18] Gaspar N, Ren XJ, Smith CW, Grima JN, Evans KE. Novel honeycombs with auxetic behaviour. Acta Mater 2005;53:2439-45. 
[19] Scarpa F. Auxetic materials for bioprostheses. IEEE Signal Process Mag 2008:25:126-8.

[20] Reis FD, Ganghoffer JF. Equivalent mechanical properties of auxetic lattices from discrete homogenization. Comput Mater Sci 2012;51:314-21.

[21] Boldrin L, Scarpa F, Rajasekaran R. Thermal conductivities of iso-volume centre-symmetric honeycombs. Compos Struct 2014;113:498-506.

[22] Sarker P, Begum M, Nasrin S. Fibre reinforced polymers for structural retrofitting: a review. J Civil Eng 2011;39(1):49-57.

[23] Saafi M. Design and fabrication of FRP grids for aerospace and civil engineering applications. J Aerosp Eng 2000;13(4):144-9.

[24] Gudonis E, Timinskar E, Gribniak V, Kaklauskas G, Arnautov A, Tamulenas V. FRP reinforcement for concrete structures: state-of-the-art review of application and design. Eng Struct Technol 2013;5(4):147-58.

[25] Yan L, Chouw N, Jayaraman K. Effect of UV and water spraying on the mechanical properties of flax fabric reinforced polymer composites used for civil engineering applications. Mater Des 2015;71:17-25.

[26] Turgay T, Polar Z, Koksal HO, Doran B, Karakoc C. Compressive behaviour of large scale square reinforced concrete columns confined with carbon fibre reinforced polymer jackets. Mater Des 2010;31(1):357-64.

[27] Einde LVD, Zhao L, Seible F. Use of FRP composites in civil structural applications. Constr Build Mater 2003;17:389-403.

[28] Ahmadi MS, Johari MS, Sadighi M, Esfandeh M. An experimental study on mechanical properties of GFRP braid-pultruded composite rods. Express Polym Lett 2009;3(9):560-8.
[29] Pereira CG, Fangueiro R, Jalali S, Marques PP, Araujo M. Hybrid composite rods for concrete reinforcement. Struct Arch - Cruz (Ed.) 2010:1605-12.

[30] Rana S, Zdraveva E, Pereira C, Fangueiro R, Correia AG. Development of hybrid braided composite rods for reinforcement and health monitoring structures. Sci World J 2014:1-9.

[31] Rosada KP, Rana S, Pereira C, Fangueiro R. Self-sensing hybrid composite rod with braided reinforcement for structural health monitoring. Mater Sci Forum 2013;730-732:379-84.

[32] Cunha F, Rana S, Fangueiro R, Vasconcelos G. Excellent bonding behaviour of novel surface-tailored fibre composite rods with cementitious matrix. Bull Mater Sci 2014;37(5):1013-7.

[33] Fangueiro R, Rana S, Correia AG. Braided composite rods: innovative fibrous materials for geotechnical applications. Geomech Eng 2013;5(2):87-97.

[34] Malvar L, Crawford J, Morrill K. Use of composites to resist blast. J Compos Constr 2007:601-10.

[35] Mosallam A, Taha MMR, Kim JJ, Nasr A. Strength and ductility of RC slabs strengthened with hybrid high-performance composite retrofit system. Eng Struct 2012;36:70-80.

[36] Mosallam AS, Banerjee S. Shear enhancement of reinforced concrete beams strengthened with FRP composite laminates. Composites Part B 2007;37:781-93.

[37] Buchan PA, Chen JF. Blast resistance of FRP composites and polymer strengthened concrete and masonry structures - a state-of-the-art review. Composites Part B 2007;38:509-22. 